\title{
Allomyrina Dichotoma Larvae Regulate Food Intake and Body Weight in High Fat Diet-Induced Obese Mice Through mTOR and Mapk Signaling Pathways
}

\author{
Jongwan Kim ${ }^{1}$, Eun-Young Yun ${ }^{2}$, Seong-Won Park ${ }^{3}$, Tae-Won Goo ${ }^{4, *}$ and Minchul Seo ${ }^{2, *}$ \\ 1 Department of Anatomy, Graduate School of Dongguk University College of Medicine, Gyeongju 38066, \\ Korea; kimjw3189@naver.com \\ 2 Department of Agricultural Biology, National Academy of Agricultural Science, RDA, Wanju-gun 55365, \\ Korea; yuney@korea.kr \\ 3 Department of Biotechnology, Catholic University of Daegu, Daegu 38430, Korea; microsw@cu.ac.kr \\ 4 Department of Biochemistry, Dongguk University College of Medicine, Gyeongju 38066, Korea \\ * Correspondence: gootw@dongguk.ac.kr (T.-W.G.); nansmc@hanmail.net (M.S.); \\ Tel.: +82-54-703-7801 (T.-W.G.); +82-63-238-2980 (M.S.)
}

Received: 22 December 2015; Accepted: 4 February 2016; Published: 18 February 2016

\begin{abstract}
Recent evidence has suggested that the Korean horn beetle (Allomyrina dichotoma) has anti-hepatofibrotic, anti-neoplastic, and antibiotic effects and is recognized as a traditional medicine. In our previous works, Allomyrina dichotoma larvae (ADL) inhibited differentiation of adipocytes both in vitro and in vivo. However, the anorexigenic and endoplasmic reticulum(ER) stress-reducing effects of ADL in obesity has not been examined. In this study, we investigated the anorexigenic and ER stress-reducing effects of ADL in the hypothalamus of diet-induced obese (DIO) mice. Intracerebroventricular (ICV) administration of ethanol extract of ADL (ADE) suggested that an antagonizing effect on ghrelin-induced feeding behavior through the mTOR and MAPK signaling pathways. Especially, ADE resulted in strong reduction of ER stress both in vitro and in vivo. These findings strongly suggest that $\mathrm{ADE}$ and its constituent bioactive compounds are available and valuable to use for treatment of various diseases driven by prolonged ER stress.
\end{abstract}

Keywords: Allomyrina dichotoma larvae; diet-induced obesity; ER stress; hypothalamus; appetite

\section{Introduction}

Obesity is widely recognized as the largest and fastest growing public health problem in the world. Obesity is caused by an imbalance between energy intake and expenditure and results in major comorbidities, including metabolic syndrome, hypertension, type 2 diabetes, stroke, cancer, and dyslipidemia [1-3]. Although anti-obesity drugs were heralded as an answer to the obesity problem in the past, they have demonstrated inconsistency and side effects. Therefore, new treatments for obesity that are both better tolerated and more efficacious are urgently needed. For decades, bioactive products have been identified and isolated from a variety of sources such as living organisms and are widely used in traditional medicine and the food industry [4,5]. Among them, insects have gained attention as a source of effective bioactive products [6]. Although there is a lack of scientific evidence regarding the safety and beneficial effects of insects, numerous insect species are used as a traditional food or medicine in many countries.

Allomyrinal dichotoma (A. dichotoma) is a species of rhinoceros beetle and widely used in traditional medicine for its anti-diabetic, anti-hepatofibrotic, anti-neoplastic, and anti-obesity effects $[4,5,7,8]$. The Food and Agriculture Organization of the United Nations (FAO) reported the possibility of using edible insects in human dietary supplements in the future. Despite growing interest 
in insect-based bioactive products, the biological activities of insect-based products have rarely been studied. In previous studies, we reported that $A$. dichotoma larvae (ADL) inhibit in vitro and in vivo differentiation of adipocytes via downregulation of transcription factors, peroxisome proliferator-activated receptor- $\gamma(\operatorname{PPAR} \gamma)$, and CCAAT/enhancer binding protein- $\alpha(\mathrm{C} / \mathrm{EBP} \alpha)[7,9]$.

The hypothalamus plays a central role in the regulation of feeding behavior and energy balance by controlling appetite regulatory neuropeptides and specific neuronal excitations [10,11]. However, disruption of these physiological functions of the hypothalamus has been implicated in various diseases, such as diabetes mellitus, neurodegenerative disease, ischemia, prion disease, and cystic fibrosis [12,13]. In particular, hypothalamic ER stress has been suggested to cause feeding behavior disorder and glucose dysregulation for promotion of obesity and diabetes [14-16]. Therefore, sustaining the functional roles of hypothalamic neurons may be beneficial for hypothalamic regulation of energy balance.

In the present study, we investigated the appetite regulatory effect of natural products extracted from A. dichotoma larvae (ADE) on the hypothalamus, a section of the brain responsible for homeostasis, of high-fat-induced obese mice since there has been no study elucidating the direct effect of ADE on appetite control in the hypothalamus. We determined food intake, body weight, appetite regulatory neuropeptides, and ER stress in mice fed high-fat diets with or without ADE. Our results demonstrate the potential of ADE as a novel treatment option for anorexigenic function in high-fat-induced obese mice via reduction of ER stress.

\section{Materials and Methods}

\subsection{Reagents and Cells}

DMSO was purchased from Sigma-Aldrich (Sigma-Aldrich, St Louis, MO, USA). QGreenTM $2 X$ SybrGreen qPCR Master Mix was purchased from CellSafe (CellSafe, Suwon, Korea). Mouse hypothalamic GT1-7 cells were maintained in Dulbecco's modified Eagle's media (Gibco, Rockville, MD, USA) supplemented with 10\% heat-inactivated fetal bovine serum (FBS) (Gibco, Grand Island, NY, USA), $100 \mathrm{U} / \mathrm{mL}$ of penicillin, and $100 \mu \mathrm{g} / \mathrm{mL}$ of streptomycin (Gibco, Grand Island, NY, USA).

\subsection{Preparation of Allomyrina Dichotoma Larvae Extract ( $A D E)$}

Freeze-dried ADL (fdADL), ground to a powder and sterilized, was provided by World Way Co. (Yeongi, Korea). fdADL was mixed with ethanol ( $1 \mathrm{~g}$ of $\mathrm{fdADL} / \mathrm{mL}$ of ethanol) and incubated at RT for $30 \mathrm{~min}$ after ultrasonication ( $250 \mathrm{~J}, 10 \mathrm{~s}$, two times). After incubation, the supernatant was filtered and completely dried using a rotary evaporator. Dried ethanol extract of ADL was dissolved in $20 \%$ DMSO.

\subsection{MTT Assay}

Cell viability was determined by 3-(4,5-dimet hylthiazol-2-yl)-2,5-diphenyltetrazolium bromide (MTT) assay. Hypothalamic neuronal GT1-7 cells were seeded in triplicate at a density of $1 \times 10^{4}$ cells per well on a 96-well plate. After treatment, culture media were removed and MTT $(0.5 \mathrm{mg} / \mathrm{mL})$ added, followed by incubation at $37^{\circ} \mathrm{C}$ for $2 \mathrm{~h}$ in a $\mathrm{CO}_{2}$ incubator. After dissolving the insoluble crystals that formed in DMSO, absorbance was measured at $570 \mathrm{~nm}$ using a microplate reader (Anthos Labtec Instruments, Wals, Austria).

\subsection{Mice}

Male C57BL/6J mice (7 weeks of age) were obtained from Japan SLC (Hamamatsu, Japan). Mice were allowed free access to standard chow diet and water for 1 week. To generate diet-induced obesity (DIO), 8-week-old mice were fed a high-fat diet (HFD, 60\% fat, D12492; Research Diets, New Brunswick, NJ, USA) for 8 weeks. Lean control mice were fed a low-fat diet (LFD, 10\% fat, D12450B; Research Diets) for the same period. The mice were placed in a controlled temperature room $\left(23^{\circ} \mathrm{C}\right)$ with a $12-\mathrm{h}$ 
light/12-h dark cycle with free access to food and water. All procedures followed the Principles of Laboratory Animal Care (NIH, Washington, DC, USA) and were approved by the Institution Animal Care and Use Committee of College of Medicine, Dongguk University.

\subsection{Intracerebro-Ventricular Cannulation and ADE Administration}

Mice were implanted with a 26-gauge stainless guide cannular ( $5 \mathrm{~mm}$ bellow pedestal; C315G, Plastics one, Roanoke, VA, USA) into the third ventricle under stereotaxic control using a stereotaxic apparatus (coordinates from Bregma: anteroventral, $-1.8 \mathrm{~mm}$; lateral, $0.0 \mathrm{~mm}$; dorsoventral, $5.0 \mathrm{~mm}$ ) through a hole created in the skull with a micro driller. The cannula was secured to the skull with dental cement and capped with a dummy cannular (C315DC, Plastic one) that extended $0.5 \mathrm{~mm}$ below the guide cannular. Animals were weighed daily, and any animal showing signs of illness or weight loss was removed from the study and euthanized. At 7 days after ICV cannulation, HFD $(n=20)$ and LFD $(n=20)$ mice were divided into two groups. The first group of HFD $(n=10)$ and LFD mice $(n=10)$ was infused with $1 \mu \mathrm{L}$ of $20 \%$ DMSO as a vehicle, whereas the second group of $\operatorname{HFD}(n=10)$ and LFD $(n=10)$ mice was infused with $1 \mu \mathrm{L}$ of ADE $(10 \mathrm{mg} / \mathrm{mL})$. All ICV injections were made using a 33-gauge internal cannular (C315I, Plastic one) that extended $0.5 \mathrm{~mm}$ below the guide cannular, connected by a cannular connector to a $5 \mu \mathrm{L}$ Hamilton syringe and infused over $5 \mathrm{~min}$. At $12 \mathrm{~h}$ after $\mathrm{ADE}$ infusion, hypothalamus were dissected and flash frozen in liquid nitrogen and kept in $-80^{\circ} \mathrm{C}$ until further processing.

\subsection{Western Blot Analysis}

Tissue or cells were lysed in RIPA lysis buffer ( $50 \mathrm{mM}$ Tris- $\mathrm{HCl}, \mathrm{pH} 8.0,150 \mathrm{mM} \mathrm{NaCl}, 0.02 \%$ sodium azide, $0.1 \%$ SDS, $1 \%$ NP-40, $0.5 \%$ sodium deoxycholate, and $1 \mathrm{mM}$ phenylmethylsulfonyl fluoride). Protein concentrations of cell lysates were measured using a Bio-Rad protein assay kit (Bio-Rad, Hercules, CA, USA). Equal amounts of protein were separated by $8 \%$ or $12 \%$ SDS-PAGE and transferred to PVDF membranes (Bio-rad, Hercules, CA, USA). Membranes were blocked with $5 \%$ skim milk and sequentially incubated with primary antibodies (mouse monoclonal anti-CHOP antibody (1:1000; Cell Signaling Technology, Danvers, MA, USA); rabbit polyclonal anti-phospho-eIF2 $\alpha$ antibody (1:1000; Cell Signaling Technology, Danvers, MA, USA); rabbit polyclonal anti-eIF2 $\alpha$ antibody (1:1000; Cell Signaling Technology, Danvers, MA, USA); mouse monoclonal anti-Ero1L antibody (1:1000; Abnova, Taipei, Taiwan); mouse monoclonal anti-PDI antibody (1:1000; Enzo Life Sciences, Inc., Plymouth Meeting, PA, USA); rabbit monoclonal anti-phospho-Stat3 (Tyr705) (1:1000; Cell Signaling Technology, Danvers, MA, USA); mouse monoclonal anti-Stat3 (1:1000; Cell Signaling Technology, Danvers, MA, USA); rabbit polyclonal anti-SOCS3 antibody (1:1000; Cell Signaling Technology, Danvers, MA, USA); $\alpha$-tubulin antibody (1:2000; Sigma-Aldrich, St Louis, MO, USA), and HRP-conjugated secondary antibody (1:10,000; anti-mouse and rabbit-IgG antibody; Amersham Biosceinces, Piscataway, NJ, USA )), followed by detection using an ECL detection kit (Invitrogen, Waltham, MA, USA).

\subsection{Reverse Transcription-PCR}

Total RNA was extracted from tissue or cells with an RNeasy Mini Kit (Qiagen, Hilden, Germany), according to the manufacturer's instructions. An aliquot of RNA was subjected to 1\% agarose gel electrophoresis to confirm integrity. cDNA was synthetized with M-MLV Reverse Transcriptase (Promega, Madison, WI, USA) and oligo(dT) primers after DNase I treatment (Invitrogen, Life Technologies). Real-time PCR was performed using the specific primer set in Table 1. Traditional PCR amplification was carried out at an annealing temperature of $60{ }^{\circ} \mathrm{C}$ for 27 cycles using the specific primer set in Table 1. For analysis of PCR products, $10 \mu \mathrm{L}$ of each PCR product was electrophoresed on a $1 \%-2.5 \%$ agarose gel and detected under UV light. Gapdh was used as an internal control. 
Table 1. DNA primers for PCR.

\begin{tabular}{|c|c|c|}
\hline Mouse cDNAs & Primer Sequences & GenBank Accession No. \\
\hline \multicolumn{3}{|c|}{ For Real-time PCR } \\
\hline$X b p-1 s$ & $\begin{array}{l}\text { Forward, 5'-AGGCTTGGTGTATACATGG-3' } \\
\text { Reverse, 5'-GGTCTGCTGAGTCCGCAGCAGG-3' }\end{array}$ & NM_013842 \\
\hline Atf4 & $\begin{array}{l}\text { Forward, 5'-GCAAGGAGGATGCCTTTTC-3' } \\
\text { Reverse, 5'-GTTTCCAGGTCATCCATTCG-3' }\end{array}$ & NM_009716 \\
\hline Chop & $\begin{array}{l}\text { Forward, 5'-CCACCACACCTGAAAGCAGAA-3' } \\
\text { Reverse, 5' } \text { 5'AGGTGAAAGGCAGGGACTCA-3' }^{\prime}\end{array}$ & NM_007837 \\
\hline Grp78 & $\begin{array}{l}\text { Forward, 5'-GGCCTGCTCCGAGTCTGCTTC-3' } \\
\text { Reverse, 5'-CCGTGCCCACATCCTCCTTCT-3' }\end{array}$ & NM_022310 \\
\hline Erdj4 & $\begin{array}{l}\text { Forward, 5'-CCCCAGTGTCAAACTGTACCAG-3' } \\
\text { Reverse, 5' } \text { 5'AGCGTTTCCAATTTTCCATAAATT-3' }^{\prime}\end{array}$ & NM_013760 \\
\hline Agrp & $\begin{array}{l}\text { Forward, 5'-TAGATCCACAGAACCGCGAGT-3' } \\
\text { Reverse, 5'-GAAGCGGCAGTAGCACGTA-3' }\end{array}$ & NM_007427 \\
\hline Npy & $\begin{array}{l}\text { Forward, 5'-CTCCGCTCTGCGACACTAC-3' } \\
\text { Reverse, 5' } \text { 5'AGGGTCTTCAAGCCTTGTTCT-3' }^{\prime}\end{array}$ & NM_023456 \\
\hline Pomc & $\begin{array}{l}\text { Forward, 5'-CTGGAGACGCCCGTGTTTC-3' } \\
\text { Reverse, 5'-TGGACTCGGCTCTGGACTG-3' }\end{array}$ & NM_001278584 \\
\hline Socs3 & $\begin{array}{l}\text { Forward, 5'-GAGTACCCCCAAGAGAGCTTACTA-3' } \\
\text { Reverse, 5'-CTCCTTAAAGTGGAGCATCATACTG-3' }\end{array}$ & NM_007707 \\
\hline Gapdh & $\begin{array}{l}\text { Forward, 5'-CTTCAACAGCAACTCCCACTCTTCC-3' } \\
\text { Reverse, 5' } \text { 5'TGGGTGGTCCAGGGTTTCTTACTCCTT-3' }^{\prime}\end{array}$ & NM_001289726 \\
\hline \multicolumn{3}{|c|}{ For Traditional PCR } \\
\hline$X b p-1$ & $\begin{array}{l}\text { Forward, 5'-CAACCAGGAGTTAAGAACACG-3' } \\
\text { Reverse, 5'-AGGCAACAGTGTCAGAGTCC-3' }\end{array}$ & NM_013842 \\
\hline Atf4 & $\begin{array}{l}\text { Forward, 5'-GACCTGGAAACCATGCCAGA-3' } \\
\text { Reverse, 5'-TGGCTGCTGTCTTGTTTTGC-3' }\end{array}$ & NM_009716 \\
\hline Chop & $\begin{array}{l}\text { Forward, 5'-TCCCCAGGAAACGAAGAGGA-3' } \\
\text { Reverse, 5'-TTGAGCCGCTCGTTCTCTTC-3' }\end{array}$ & NM_007837 \\
\hline Gapdh & $\begin{array}{l}\text { Forward, 5'-GACCACAGTCCATGCCATCA-3' } \\
\text { Reverse, 5'-CATTGAGAGCAATGCCAGCC-3' }\end{array}$ & NM_001289726 \\
\hline
\end{tabular}

\subsection{Data Analysis}

All data are presented as the means \pm SDs. Comparisons between two groups were performed using the Student's $t$-test. Comparisons between three or more groups were analyzed using one-way ANOVA with Dunnett experiments. SPSS version 18.0 K (SPSS Inc., Chicago, IL, USA) was used for the analysis, and $p$ value differences of $<0.05$ were considered statistically significant.

\section{Results}

\subsection{High Fat Diet-Induced Obesity Induces Hypothalamic Endoplasmic Reticulum Stress}

To examine whether obesity induces ER stress in hypothalamus, we fed male C57BL/6J mice a high-fat diet (HFD; 60\% kcal from fat) and low-fat diet (LFD; 10\% kcal from fat) for 8 weeks (Figure 1A). Body weight significantly increased in high-fat-diet-induced mice during the study period compared with low-fat-diet-induced mice (Figure 1B). We then performed quantitative PCR analysis of ER stress responsive markers, such as spliced X-box binding protein 1 (Xbp-1s), activating transcription factor 4 (Atf4), c/EBP-homologous protein (Chop), $78 \mathrm{kDa}$ glucose-regulated protein (Grp78), and ER DnaJ homolog 4 (Erdj4), after mRNA isolation from the hypothalamus of mice fed a high-fat diet or 
low-fat diet for 8 weeks. The expression levels of ER stress responsive markers were dramatically upregulated in high-fat-diet-induced mice (Figure 1C). Taken together, these results indicate that the persistence of obesity gradually induces ER stress, followed by activation of the UPR signaling pathway in the hypothalamus.

\subsection{Central Administration of ADE Reduces Food Intake and Body Weight through Regulation of Appetite-Related Neuropeptides in High Fat Diet-Induced Mice}

To examine the possibility that ADE as a natural food supplement can regulate appetite, we tested cytotoxicity of ADE before central administration using hypothalamic neuronal GT1-7 cells. The cytotoxicity of ADE was determined by 3-(4,5-dimethylthiazol-2-yl)-2,5-diphenyltetrazolium bromide (MTT) assay after treatment with various concentrations of ADE (0.01-5 mg/mL). As a result, up to $5 \mathrm{mg} / \mathrm{mL}$ of ADE showed no cytotoxic effect on hypothalamic neuronal GT1-7 cells [17]. To determine whether or not central administration of ADE regulates food intake and body weight in high-fat-diet-induced mice, we administrated a single dose of ADE ( $1 \mu \mathrm{L}$ of $10 \mathrm{mg} / \mathrm{mL}$ ADE) into the third ventricle. Administration of ADE significantly reduced food intake and body weight during $24 \mathrm{~h}$ compared to the vehicle control, which was evident $2 \mathrm{~h}$ after infusion and was consistent after 24 h (Figure 2A,B, Supplementary Figure S1A,B). Next, we evaluated whether or not the anorexigenic action of ADE is associated with changes in ARC-derived neuropeptides. As shown in Figure 2C, central administration of ADE decreased the mRNA expression levels of Agrp and Npy, whereas Pomc expression increased in high-fat-diet-induced mice. However, low-fat-diet-induced mice showed no changes (Supplementary Figure S1C).

A

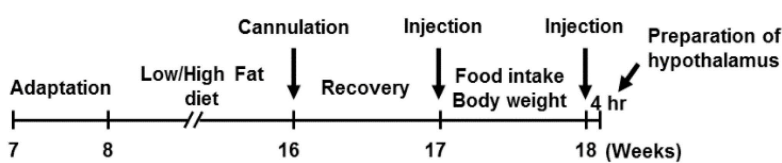

B
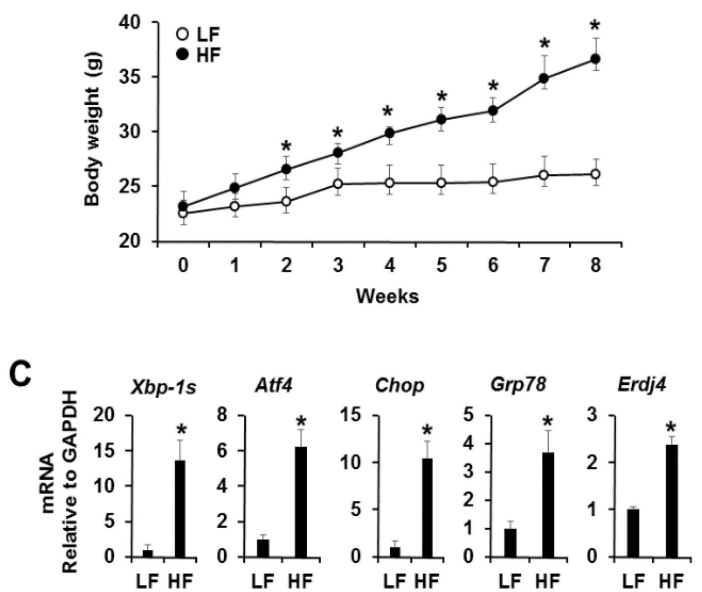

Figure 1. Increased hypothalamic ER stress in mice fed a high-fat diet. (A) Experimental timeline of the experimental procedure; (B) Time dependence of body weight in low fat and high-fat-diet-induced mice. At 8 weeks of age, mice fed a high-fat diet showed a $43 \%$ increase in body weight compared with those fed a low-fat diet. The results are means \pm SDs $(n=10) ;{ }^{*} p$ values of $<0.05$ indicate significant difference from low-fat diet-induced mice; (C) mRNA expression levels of ER stress responsive markers in low fat and high-fat-diet-induced mice. mRNA expression levels of ER stress responsive markers were dramatically upregulated in high-fat-diet-induced obese mice. The results are means \pm SDs $(n=10) ;{ }^{*} p$ values of $<0.05$ indicate significant difference from low-fat-diet-induced mice. LF, low-fat diet. HF, high-fat diet. 


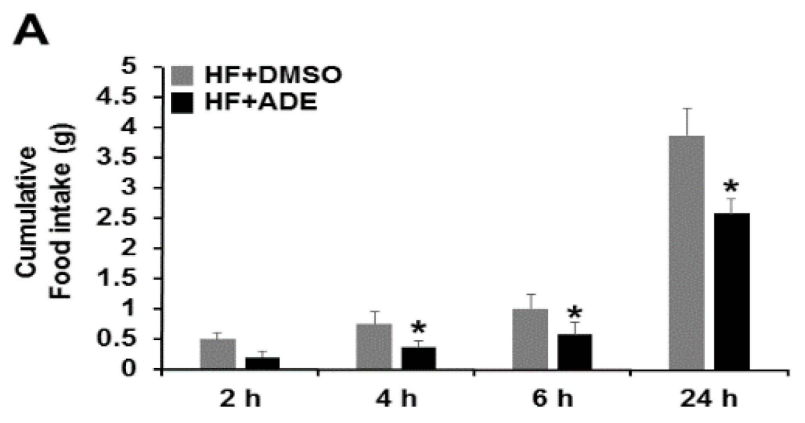

B
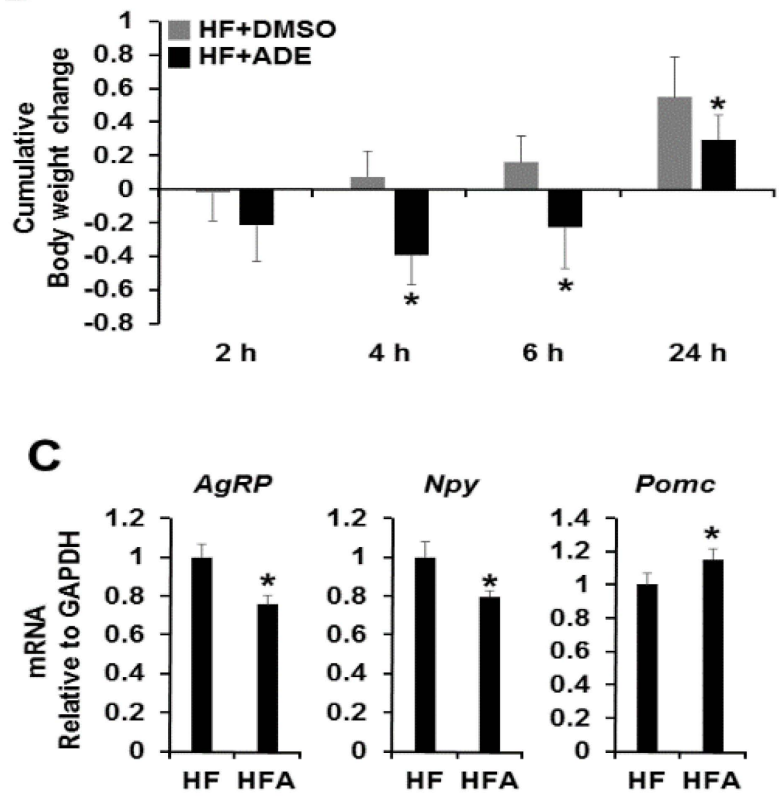

Figure 2. Effects of central administration of ADE on food intake and body weight. The average cumulative food intake (A) and body weight (B) were measured in high-fat-diet-induced mice ICV administration with ADE ( $1 \mu \mathrm{L}$ of $10 \mathrm{mg} / \mathrm{mL})$ or DMSO $(1 \mu \mathrm{L}$ of $20 \%$ DMSO) during the experimental period. The results are means $\pm \operatorname{SDs}\left(n=10\right.$ per group); ${ }^{*} p$ values of $<0.05$ indicate significant difference from administration with DMSO (1 $\mu \mathrm{L}$ of $20 \%$ DMSO). (C) Effects of ICV administration of ADE $(1 \mu \mathrm{L}$ of $10 \mathrm{mg} / \mathrm{mL})$ on hypothalamic mRNA expression levels of neuropeptides. The results are means \pm SDs $\left(n=10\right.$ per group); ${ }^{*} p$ values of $<0.05$ indicate significant difference from administration with DMSO ( $1 \mu \mathrm{L}$ of $20 \%$ DMSO). ADE, ethanol extract of Allomyrina dichotoma larvae. HF, high-fat diet with DMSO. HFA, high-fat diet with ADE.

\subsection{Central Administration of ADE Reduces Hypothalamic Endoplasmic Reticulum Stress}

In previous works, under diet-induced obesity (DIO) conditions, orexigenic neuropeptides (AgRP and NPY) were induced while anorexigenic neuropeptides $(\alpha-\mathrm{MSH})$ were reduced by hypothalamic ER stress [18-20]. To examine whether or not ADE can regulate hypothalamic ER stress in high-fat-diet-induced mice, we administrated ADE and vehicle control into the third ventricle of high fat or low-fat-diet-induced obese mice. Expression levels of ER stress responsive markers (phosphor-eIF2a and CHOP) and ER chaperone/foldases (Bip, Ero1L, and PDI) were dramatically reduced in the hypothalamus in high fat diet-induced obese mice (Figure 3A). Furthermore, mRNA expression levels of ER stress responsive genes (Xbp-1s, Atf4, Chop, Grp78, and Erdj4) were significantly reduced in ADE-administrated high fat diet-induced obese mice compared with vehicle control (Figure 3B). However, low-fat-diet-induced mice showed no changes due to lack of ER stress 
(Supplementary Figures S2A,B and S3). These results indicate that ADE can forcefully reduce ER stress induced by a high-fat diet in the hypothalamus.

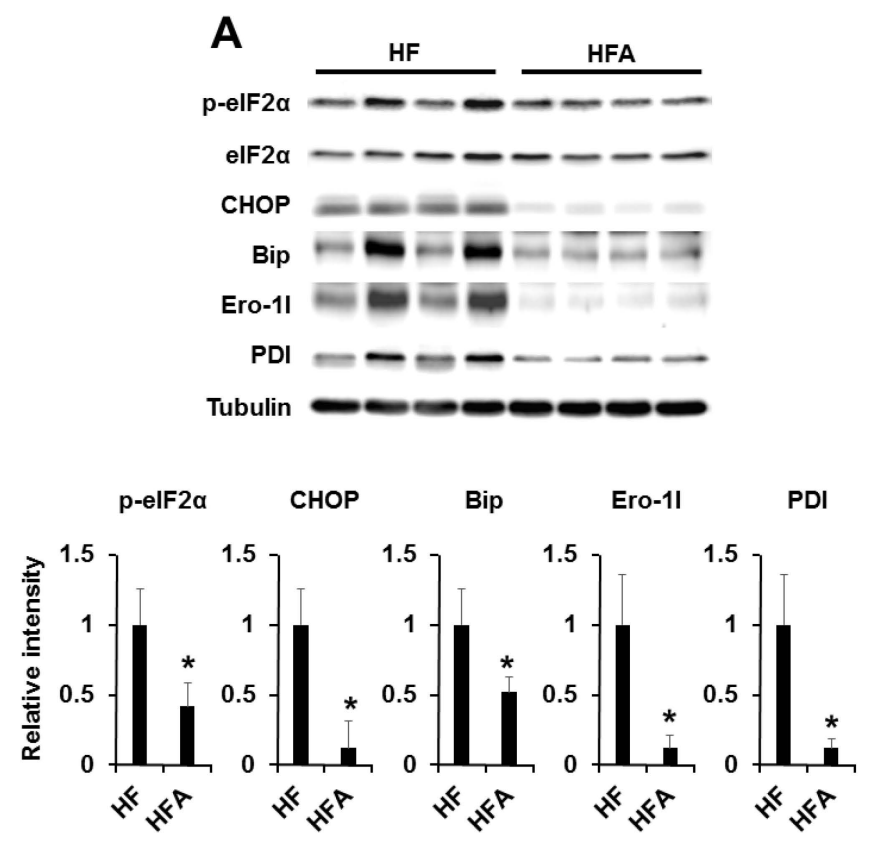

B

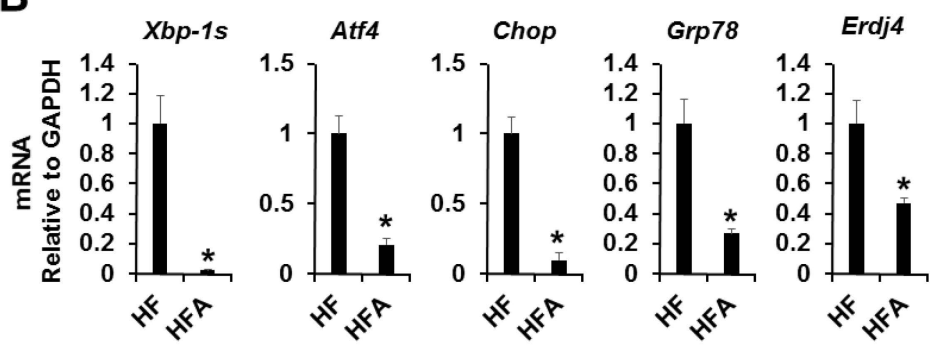

Figure 3. Effects of central administration of ADE on ER stress responsive markers and ER chaperone/foldases expression. (A) Effects of ICV administration of ADE ( $1 \mu \mathrm{L}$ of $10 \mathrm{mg} / \mathrm{mL})$ on hypothalamic ER stress responsive markers and ER chaperone/foldases. The results of densitometric analysis (lower) are means \pm SDs $(n=10) ;{ }^{*} p$ values of $<0.05$ indicate significant difference from administration with DMSO ( $1 \mu \mathrm{L}$ of $20 \%$ DMSO); (B) Effects of ICV administration of ADE ( $1 \mu \mathrm{L}$ of $10 \mathrm{mg} / \mathrm{mL}$ ) on hypothalamic mRNA expression levels of hypothalamic ER stress responsive markers. The results are means \pm SDs ( $n=10$ per group); * $p$ values of $<0.05$ indicate significant difference from administration with DMSO (1 $\mu \mathrm{L}$ of $20 \%$ DMSO). HF, high-fat diet with DMSO. HFA, high-fat diet with ADE.

\subsection{Central Administration of ADE Regulates Appetite through MAPK and mTOR Signaling}

Recent evidence has demonstrated that hypothalamic mammalian target of rapamycin (mTOR), a highly conserved serine-threonine kinase, signaling plays a role in modulation of feeding behavior by acting as a cellular sensor of changes in energy balance, nutrients, and growth factors [21,22]. Leptin and ghrelin seem to be powerful factors in the regulation of food intake and body weight. In the hypothalamus, activation of leptin or ghrelin receptor initiates different signaling cascades regulating food intake [23-26]. mTOR and MAPKs (ERK and p38) signaling has been previously associated with ghrelin [27-31]. For example, central administration of ghrelin has been reported to activate mTOR and ERK signaling to induce food intake. Therefore, we determined which signaling cascades are linked to appetite control after central administration of ADE. Firstly, we investigated leptin signaling with 
phospho-Stat3, -JAK2, and SOCS3 antibody. However, phosphorylation or expression of these proteins was unchanged. Secondly, we determined ghrelin signaling downstream of mTOR (phospho-S6K1 and -S6) and MAPKs (phospho-ERK and -p38) (Figure 4 and Supplementary Figure S4). As shown in Figure 4, S6K1, S6, and ERK phosphorylation levels were significantly reduced after administration of ADE compared with vehicle control. However, phosphorylation of p38MAPK was elevated after ADE administration in mice fed a high-fat diet. These results assume that ADE reduces appetite by antagonizing ghrelin signaling cascades rather than leptin signaling, and mTOR and MAPK signaling pathways were necessary for appetite regulation of ADE in the hypothalamus.
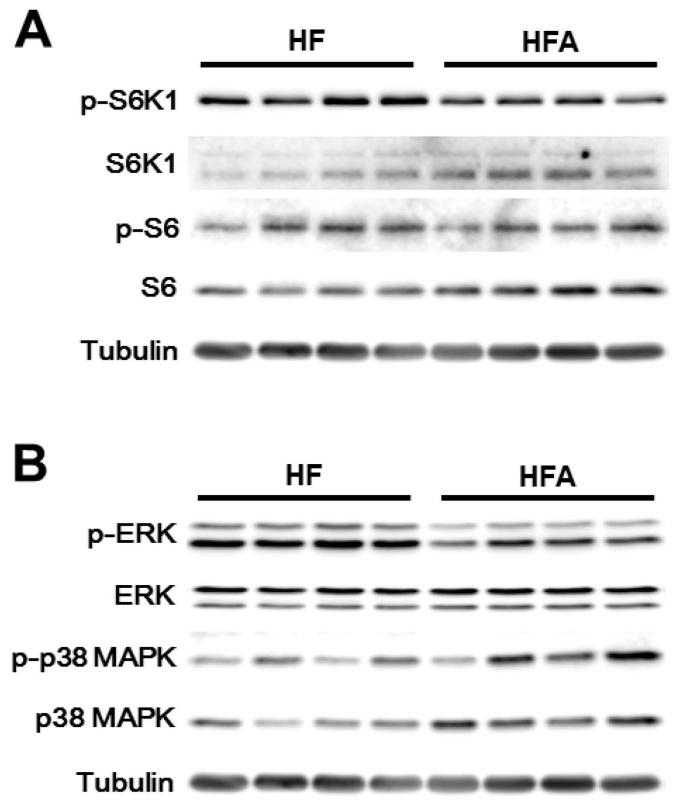
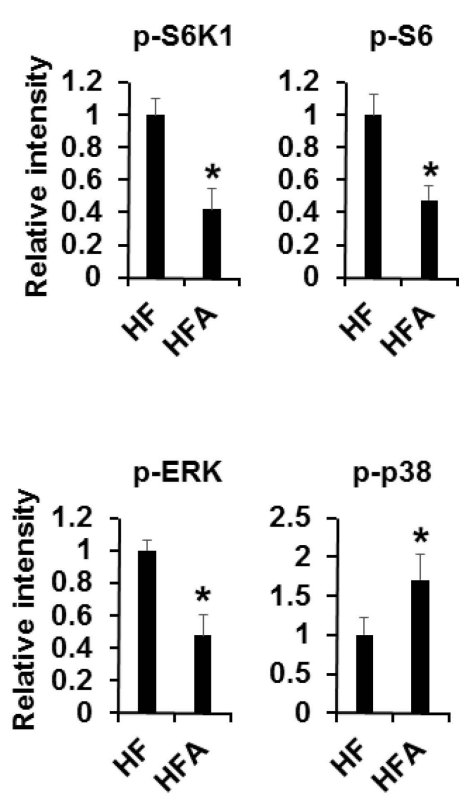

Figure 4. Central administration of ADE reduces ghrelin signaling through mTOR and ERK signaling pathways in mice fed a high-fat diet. (A) Effects of ICV administration of ADE (1 $\mu \mathrm{L}$ of $10 \mathrm{mg} / \mathrm{mL})$ on mTOR signaling pathways. The results of densitometric analysis (right) are means \pm SDs $(n=10$ per group); ${ }^{*} p$ values of $<0.05$ indicate significant difference from administration with DMSO $(1 \mu \mathrm{L}$ of $20 \%$ DMSO); (B) Effects of ICV administration of ADE (1 $\mu \mathrm{L}$ of $10 \mathrm{mg} / \mathrm{mL})$ on MAPK signaling pathways. The results of densitometric analysis (right) are means $\pm \operatorname{SDs}(n=10) ;{ }^{*} p$ values of $<0.05$ indicate significant difference from administration with DMSO $(1 \mu \mathrm{L}$ of $20 \% \mathrm{DMSO})$. HF, high-fat diet with DMSO. HFA, high-fat diet with ADE.

\section{Discussion}

The hypothalamus is considered a key player in the regulation of food intake and body weight, although hypothalamic dysfunction may occur in a chronic energy excess state [20,32]. Under obese conditions induced by pharmacologic or genetic causes, endoplasmic reticulum (ER) stress in the hypothalamus causes central leptin and insulin resistance, resulting in increased food intake, hypertension, and glucose intolerance, whereas reduction of ER stress significantly attenuates these metabolic derangements [33,34]. Beetle species, a very well-known insect, is widely used in Oriental medicine to treat various diseases such as diabetes and hepatofibrosis in Asian countries [8,35]. Insects can be used as a health food supplement or functional food, as they are rich in protein, vitamins, minerals, fiber, and unsaturated fatty acids [36-38]. Previous works reported that several kinds of insect extracts could be used as anti-obesity and liver disease treatment agents [7,9,39].

In this study, we demonstrated the functional effects of ADE on ER stress and appetite regulatory neuropeptide processing in obesity. In diet-induced obesity (DIO), the appetite regulatory $\alpha$-melanocyte-stimulating hormone $(\alpha-\mathrm{MSH})$ is downregulated, whereas appetite-inducing 
neuropeptide Y (NPY) and aqouti-related protein (AgRP) are induced [18-20]. To study the effects of ADE on appetite control, ADE was injected with ICV, and food intake and body weight changes were measured (Figure 2A,B). As a result, food intake and body weight were markedly reduced after ADE administration compared with vehicle control, which was evident $2 \mathrm{~h}$ after infusion and was consistent after $24 \mathrm{~h}$. Furthermore, we quantified the mRNA expression levels of Npy, Agrp, and Pomc by quantitative PCR. As shown in Figure 2C, Npy and Agrp mRNA expression levels were reduced, whereas Pomc mRNA level increased after ADE administration. From these results, we assume that the appetite reducing effect of ADE is mediated by restoration of DIO-induced leptin resistance accompanied by reduction of ER stress on the hypothalamus. Thus, we investigated expression levels of ER stress markers and chaperones using Western blot analysis or quantitative PCR. As shown in Figure 3, ER stress markers and chaperones were dramatically downregulated upon ADE infusion, whereas leptin resistance was not restored.

Ghrelin expression was elevated upon fasting and reduced upon feeding in normal and genetically obese rodents [40-42]. Based on these findings, we speculate that reduction of food intake and body weight by ADE may be due to antagonization of ghrelin function. In previous works, ICV injection of ghrelin induced orexigenic action by increasing mTOR and ERK signaling pathways $[27,28,43,44]$. Additionally, ghrelin was shown to inhibit 38 MAPK activation in oligodendrocytes and other types of cells $[30,31]$. Therefore, we determined levels of S6K1 and S6 phosphorylation, downstream signaling cascades of mTOR, and phosphorylation of MAPKs (ERK and p38) (Figure 4). Central administration of ADE significantly downregulated phosphorylation of S6K1, S6, and ERK as well as upregulation of p38 MAPK in mice fed a high-fat diet. However, low-fat-diet-induced mice showed no changes (Supplementary Figure S4). These result indicate that ADE reduces appetite by antagonizing ghrelin signaling cascades rather than leptin signaling, and mTOR and ERK signaling are necessary for appetite regulation of $\mathrm{ADE}$ in the hypothalamus in mice fed a high-fat diet.

In summary, our most significant finding is that ethanol extract of Allomyrina dichotoma larvae (ADE) has an anorexigenic effect through regulation of mTOR and MAPK pathways, resulting in reduced food intake and body weight changes accompanied by reduced ER stress. We speculate that the anorexigenic effect of ADE is due to antagonization of ghrelin-induced feeding behavior. Furthermore, ADE showed the strongest reducing effect on ER stress both in vitro and in vivo (Figure 3 and Supplementary Figure S2). Accumulating evidence suggests that chronic activation of ER stress contributes to the pathogenesis of many diseases, including neurodegenerative diseases, bipolar disorder, diabetes mellitus, atherosclerosis, inflammation, ischemia, heart diseases, liver and kidney disease, and cancer $[45,46]$. As research on ER stress-related diseases has recently increased, these results strongly suggest that ADE is available and valuable to use for treatment of various diseases driven by prolonged ER stress. This study demonstrates the anorexigenic and ER stress-reducing effects of ADE in the central nervous system and provides a strong possibility for the implications of insect-derived multiple compounds for the therapeutic purposes in patients. However, this study was limited to the administration of ADE, an anti-obesity drug, via the third ventricle, which grants further investigation to validate the effects via other routes of administration including oral. Furthermore, fractionation of $\mathrm{ADE}$ is also warranted to examine the proper components of the ADE responsible for these effects, as well as to provide strong evidence of the anorexigenic and ER stress-reducing effects of ADE on hypothalamic ER stress-driven metabolic disorders.

\section{Conclusions}

Intracerebroventricular (ICV) administration of the ADE had an antagonizing effect on ghrelin-induced feeding behavior through mTOR and MAPK signaling pathways. These findings strongly suggest that ADE and its constituent bioactive compounds are available and valuable to use for treatment of various diseases driven by prolonged ER stress

Supplementary Materials: The following are available online at http://www.mdpi.com/2072-6643/8/2/100/s1: Figure S1: Effects of central administration of ADE on food intake and body, Figure S2: Effects of ADE on ER 
stress responsive marker expression, Figure S3: Effects of central administration of ADE on ER stress responsive markers and ER chaperone/foldases expression in mice fed a low-fat diet, Figure S4: Central administration of ADE reduces ghrelin signaling through mTOR and ERK signaling pathways in mice fed a low-fat diet.

Acknowledgments: This study was supported by the Bio-industry Technology Development Program (315030-3), Ministry for Food, Agriculture, Forestry and Fisheries, Republic of Korea.

Author Contributions: J.K. and M.S. performed the experiments, analyzed the data, and prepared the manuscript. E.Y.Y., T.W.G., and S.W.P. provided reagents and analyzed the data. M.S. and T.W.G directed the study and were involved in all aspects of the experimental design, data analysis and manuscript preparation. All authors critically reviewed the text and figures.

Conflicts of Interest: The authors declare no conflict of interest.

\section{References}

1. Guzman, A.K.; Ding, M.; Xie, Y.; Martin, K.A. Pharmacogenetics of obesity drug therapy. Curr. Mol. Med. 2014, 14, 891-908. [CrossRef] [PubMed]

2. Rodgers, R.J.; Tschop, M.H.; Wilding, J.P. Anti-obesity drugs: Past, present and future. Dis. Models Mech. 2012, 5, 621-626. [CrossRef] [PubMed]

3. Flegal, K.M.; Graubard, B.I.; Williamson, D.F.; Gail, M.H. Cause-specific excess deaths associated with underweight, overweight, and obesity. Jama 2007, 298, 2028-2037. [CrossRef] [PubMed]

4. Sagisaka, A.; Miyanoshita, A.; Ishibashi, J.; Yamakawa, M. Purification, characterization and gene expression of a glycine and proline-rich antibacterial protein family from larvae of a beetle, Allomyrina dichotoma. Insect Mol. Biol. 2001, 10, 293-302. [CrossRef] [PubMed]

5. Miyanoshita, A.; Hara, S.; Sugiyama, M.; Asaoka, A.; Taniai, K.; Yukuhiro, F.; Yamakawa, M. Isolation and characterization of a new member of the insect defensin family from a beetle, Allomyrina dichotoma. Biochem. Biophys. Res. Commun. 1996, 220, 526-531. [CrossRef] [PubMed]

6. Suh, H.J.; Kim, S.R.; Lee, K.S.; Park, S.; Kang, S.C. Antioxidant activity of various solvent extracts from Allomyrina dichotoma (Arthropoda: Insecta) larvae. J. Photochem. Photobiol. B Biol. 2010, 99, 67-73. [CrossRef] [PubMed]

7. Yoon, Y.I.; Chung, M.Y.; Hwang, J.S.; Han, M.S.; Goo, T.W.; Yun, E.Y. Allomyrina dichotoma (Arthropoda: Insecta) larvae confer resistance to obesity in mice fed a high-fat diet. Nutrients 2015, 7, 1978-1991. [CrossRef] [PubMed]

8. Yoshikawa, K.; Umetsu, K.; Shinzawa, H.; Yuasa, I.; Maruyama, K.; Ohkura, T.; Yamashita, K.; Suzuki, T. Determination of carbohydrate-deficient transferrin separated by lectin affinity chromatography for detecting chronic alcohol abuse. FEBS Lett. 1999, 458, 112-116. [CrossRef]

9. Chung, M.Y.; Yoon, Y.I.; Hwang, J.S.; Goo, T.W.; Yun, E.Y. Anti-obesity effect of Allomyrina dichotoma (Arthropoda: Insecta) larvae ethanol extract on 3T3-L1 adipocyte differentiation. Entomol. Res. 2014, 44, 9-16. [CrossRef]

10. Morton, G.J.; Cummings, D.E.; Baskin, D.G.; Barsh, G.S.; Schwartz, M.W. Central nervous system control of food intake and body weight. Nature 2006, 443, 289-295. [CrossRef] [PubMed]

11. Elmquist, J.K.; Coppari, R.; Balthasar, N.; Ichinose, M.; Lowell, B.B. Identifying hypothalamic pathways controlling food intake, body weight, and glucose homeostasis. J. Comp. Neurol. 2005, 493, 63-71. [CrossRef] [PubMed]

12. Lupachyk, S.; Watcho, P.; Obrosov, A.A.; Stavniichuk, R.; Obrosova, I.G. Endoplasmic reticulum stress contributes to prediabetic peripheral neuropathy. Exp. Neurol. 2013, 247, 342-348. [CrossRef] [PubMed]

13. Cnop, M.; Foufelle, F.; Velloso, L.A. Endoplasmic reticulum stress, obesity and diabetes. Trends Mol. Med. 2012, 18, 59-68. [CrossRef] [PubMed]

14. Denis, R.G.; Arruda, A.P.; Romanatto, T.; Milanski, M.; Coope, A.; Solon, C.; Razolli, D.S.; Velloso, L.A. TNF- $\alpha$ transiently induces endoplasmic reticulum stress and an incomplete unfolded protein response in the hypothalamus. Neuroscience 2010, 170, 1035-1044. [CrossRef] [PubMed]

15. Hotamisligil, G.S. Endoplasmic reticulum stress and the inflammatory basis of metabolic disease. Cell 2010, 140, 900-917. [CrossRef] [PubMed]

16. Won, J.C.; Jang, P.G.; Namkoong, C.; Koh, E.H.; Kim, S.K.; Park, J.Y.; Lee, K.U.; Kim, M.S. Central administration of an endoplasmic reticulum stress inducer inhibits the anorexigenic effects of leptin and insulin. Obesity 2009, 17, 1861-1865. [CrossRef] [PubMed] 
17. Noh, J.H.; Yun, E.Y.; Park, H.; Jung, K.J.; Hwang, J.S.; Jeong, E.J.; Moon, K.S. Subchronic oral dose toxicity of freeze-dried powder of Allomyrina dichotoma larvae. Toxicol. Res. 2015, 31, 69-75. [CrossRef] [PubMed]

18. Cakir, I.; Cyr, N.E.; Perello, M.; Litvinov, B.P.; Romero, A.; Stuart, R.C.; Nillni, E.A. Obesity induces hypothalamic endoplasmic reticulum stress and impairs proopiomelanocortin (POMC) post-translational processing. J. Biol. Chem. 2013, 288, 17675-17688. [CrossRef] [PubMed]

19. Cao, Z.P.; Wang, F.; Xiang, X.S.; Cao, R.; Zhang, W.B.; Gao, S.B. Intracerebroventricular administration of conjugated linoleic acid (CLA) inhibits food intake by decreasing gene expression of NPY and AgRP. Neurosci. Lett. 2007, 418, 217-221. [CrossRef] [PubMed]

20. Kalra, S.P.; Dube, M.G.; Pu, S.; Xu, B.; Horvath, T.L.; Kalra, P.S. Interacting appetite-regulating pathways in the hypothalamic regulation of body weight. Endocr. Rev. 1999, 20, 68-100. [CrossRef] [PubMed]

21. Wullschleger, S.; Loewith, R.; Hall, M.N. TOR signaling in growth and metabolism. Cell 2006, 124, 471-484. [CrossRef] [PubMed]

22. Padmanabhan, R. Electron-microscopic studies on the pathogenesis of exencephaly and cranioschisis induced in the rat after neural tube closure: Role of the neuroepithelium and choroid plexus. Acta Anat. 1990, 137, 5-18. [CrossRef] [PubMed]

23. Klok, M.D.; Jakobsdottir, S.; Drent, M.L. The role of leptin and ghrelin in the regulation of food intake and body weight in humans: A Review. Obes. Rev. 2007, 8, 21-34. [CrossRef] [PubMed]

24. Sahu, A. Minireview: A hypothalamic role in energy balance with special emphasis on leptin. Endocrinology 2004, 145, 2613-2620. [CrossRef] [PubMed]

25. Sahu, A. Leptin signaling in the hypothalamus: Emphasis on energy homeostasis and leptin resistance. Front. Neuroendocrinol. 2003, 24, 225-253. [CrossRef] [PubMed]

26. Schwartz, M.W. Brain pathways controlling food intake and body weight. Exp. Biol. Med. 2001, 226, 978-981.

27. Stevanovic, D.; Trajkovic, V.; Muller-Luhlhoff, S.; Brandt, E.; Abplanalp, W.; Bumke-Vogt, C.; Liehl, B.; Wiedmer, P.; Janjetovic, K.; Starcevic, V.; et al. Ghrelin-induced food intake and adiposity depend on central mtorc1/s6k1 signaling. Mol. Cell. Endocrinol. 2013, 381, 280-290. [CrossRef] [PubMed]

28. Martins, L.; Fernandez-Mallo, D.; Novelle, M.G.; Vazquez, M.J.; Tena-Sempere, M.; Nogueiras, R.; Lopez, M.; Dieguez, C. Hypothalamic mtor signaling mediates the orexigenic action of ghrelin. PLoS ONE 2012, 7, e46923. [CrossRef] [PubMed]

29. Stevanovic, D.; Starcevic, V.; Vilimanovich, U.; Nesic, D.; Vucicevic, L.; Misirkic, M.; Janjetovic, K.; Savic, E.; Popadic, D.; Sudar, E.; et al. Immunomodulatory actions of central ghrelin in diet-induced energy imbalance. Brain Behav. Immun. 2012, 26, 150-158. [CrossRef] [PubMed]

30. Lee, J.Y.; Oh, T.H.; Yune, T.Y. Ghrelin inhibits hydrogen peroxide-induced apoptotic cell death of oligodendrocytes via erk and p38MAPK signaling. Endocrinology 2011, 152, 2377-2386. [CrossRef] [PubMed]

31. Hu, C.Z.; Cao, Y.L.; Huo, H.Y.; Zhao, W.H.; Hu, J. Inhibitory effect of ghrelin on nicotine-induced VCAM-1 expression in human umbilical vein endothelial cells. J. Cardiovasc. Pharmacol. 2009, 53, 241-245. [CrossRef] [PubMed]

32. Kim, H.K.; Youn, B.S.; Shin, M.S.; Namkoong, C.; Park, K.H.; Baik, J.H.; Kim, J.B.; Park, J.Y.; Lee, K.U.; Kim, Y.B.; et al. Hypothalamic angptl4/fiaf is a novel regulator of food intake and body weight. Diabetes 2010, 59, 2772-2780. [CrossRef] [PubMed]

33. Cai, D.; Liu, T. Hypothalamic inflammation: A double-edged sword to nutritional diseases. Ann. N. Y. Acad. Sci. 2011, 1243, E1-E39. [CrossRef] [PubMed]

34. Purkayastha, S.; Zhang, H.; Zhang, G.; Ahmed, Z.; Wang, Y.; Cai, D. Neural dysregulation of peripheral insulin action and blood pressure by brain endoplasmic reticulum stress. Proc. Natl. Acad. Sci. USA 2011, 108, 2939-2944. [CrossRef] [PubMed]

35. Dobrin, P.; Canfield, T. Cuffed endotracheal tubes: Mucosal pressures and tracheal wall blood flow. Am. J. Surg. 1977, 133, 562-568. [CrossRef]

36. Youn, K.; Kim, J.Y.; Yeo, H.; Yun, E.Y.; Hwang, J.S.; Jun, M. Fatty acid and volatile oil compositions of Allomyrina dichotoma larvae. Prev. Nutr. Food Sci. 2012, 17, 310-314. [CrossRef] [PubMed]

37. Chung, M.Y.; Hwang, J.S.; Goo, T.W.; Yun, E.Y. Analysis of general composition and harmful material of Protaetia breviatarsis. J. Life Sci. 2013, 23, 664-668. [CrossRef]

38. Yoo, J.M.; Hwang, J.S.; Goo, T.W.; Yun, E.Y. Comparative analysis of nutritional and harmful components in Korean and Chinese meal worms (Tenebrio molitor). J. Korean Soc. Food Sci. Nutr. 2013, 42, $249-254$. [CrossRef] 
39. Chung, M.Y.; Kown, E.Y.; Hwang, J.S.; Goo, T.W.; Yun, E.Y. Establishment of food processing methods for larvae of Allomyrina dichotoma, Korean horn beetle. J. Life Sci. 2013, 23, 426-431. [CrossRef]

40. Moesgaard, S.G.; Ahren, B.; Carr, R.D.; Gram, D.X.; Brand, C.L.; Sundler, F. Effects of high-fat feeding and fasting on ghrelin expression in the mouse stomach. Regul. Pept. 2004, 120, 261-267. [CrossRef] [PubMed]

41. Ariyasu, H.; Takaya, K.; Hosoda, H.; Iwakura, H.; Ebihara, K.; Mori, K.; Ogawa, Y.; Hosoda, K.; Akamizu, T.; Kojima, M.; et al. Delayed short-term secretory regulation of ghrelin in obese animals: Evidenced by a specific ria for the active form of ghrelin. Endocrinology 2002, 143, 3341-3350. [CrossRef] [PubMed]

42. Toshinai, K.; Mondal, M.S.; Nakazato, M.; Date, Y.; Murakami, N.; Kojima, M.; Kangawa, K.; Matsukura, S. Upregulation of ghrelin expression in the stomach upon fasting, insulin-induced hypoglycemia, and leptin administration. Biochem. Biophys. Res. Commun. 2001, 281, 1220-1225. [CrossRef] [PubMed]

43. Komori, T.; Doi, A.; Nosaka, T.; Furuta, H.; Akamizu, T.; Kitamura, T.; Senba, E.; Morikawa, Y. Regulation of AMP-activated protein kinase signaling by AFF4 protein, member of AF4 (ALL1-fused gene from chromosome 4) family of transcription factors, in hypothalamic neurons. J. Biol. Chem. 2012, 287, 19985-19996. [CrossRef] [PubMed]

44. Mousseaux, D.; Le Gallic, L.; Ryan, J.; Oiry, C.; Gagne, D.; Fehrentz, J.A.; Galleyrand, J.C.; Martinez, J. Regulation of ERK1/2 activity by ghrelin-activated growth hormone secretagogue receptor 1a involves a PLC/PKCE pathway. Br. J. Pharmacol. 2006, 148, 350-365. [PubMed]

45. Ozcan, L.; Tabas, I. Role of endoplasmic reticulum stress in metabolic disease and other disorders. Ann. Rev. Med. 2012, 63, 317-328. [CrossRef] [PubMed]

46. Yoshida, H. ER stress and diseases. FEBS J. 2007, 274, 630-658. [CrossRef] [PubMed]

(C) 2016 by the authors; licensee MDPI, Basel, Switzerland. This article is an open access article distributed under the terms and conditions of the Creative Commons by Attribution (CC-BY) license (http:/ / creativecommons.org/licenses/by/4.0/). 